\title{
Hydro- and morphodynamics in curved river reaches - recent results and directions for future research
}

\author{
K. Blanckaert ${ }^{1,4}$, G. Constantinescu ${ }^{2}$, W. Uijttewaal ${ }^{3}$, and Q. Chen ${ }^{1}$ \\ ${ }^{1}$ State Key Laboratory of Urban and Regional Ecology, Research Centre for Eco-Environmental Sciences, \\ Chinese Academy of Sciences, Beijing, China \\ ${ }^{2}$ Department of Civil and Environmental Engineering \& IIHR-Hydroscience and Engineering, \\ The University of Iowa, Iowa, USA \\ ${ }^{3}$ Faculty of Civil Engineering and Geosciences, Delft University of Technology, Delft, the Netherlands \\ ${ }^{4}$ Laboratory of Hydraulic Constructions, Ecole Polytechnique Fédérale Lausanne, Lausanne, Switzerland
}

Correspondence to: K. Blanckaert (koen.blanckaert@epfl.ch)

Received: 25 February 2013 - Revised: 1 May 2013 - Accepted: 3 June 2013 - Published: 17 December 2013

\begin{abstract}
Curved river reaches were investigated as an example of river configurations where three-dimensional processes prevail. Similar processes occur, for example, in confluences and bifurcations, or near hydraulic structures such as bridge piers and abutments. Some important processes were investigated in detail in the laboratory, simulated numerically by means of eddy-resolving techniques, and finally parameterized in long-term and large-scale morphodynamic models. Investigated flow processes include secondary flow, largescale coherent turbulence structures, shear layers and flow separation at the convex inner bank. Secondary flow causes a redistribution of the flow and a transverse inclination of the riverbed, which favour erosion of the outer bank and meander migration. Secondary flow generates vertical velocities that impinge on the riverbed, and are known to increase the erosive capacity of the flow. Large-scale turbulent coherent structures also increase the sediment entrainment and transport capacity. Both processes are not accounted for in sediment transport formulae, which leads to an underestimation of the bend scour and the erosion of the outer bank. Eddyresolving numerical models are computationally too expensive to be implemented in long-term and large-scale morphodynamic models. But they provide insight in the flow processes and broaden the investigated parameter space. Results from laboratory experiments and eddy-resolving numerical models were at the basis of the development of a new parameterization without curvature restrictions of secondary flow effects, which is applicable in long-term and large-scale morphodynamic models. It also led to the development of a new
\end{abstract}

engineering technique to modify the flow and the bed morphology by means of an air-bubble screen. The rising air bubbles generate secondary flow, which redistributes the patterns of flow, boundary shear stress and sediment transport.

\section{Introduction}

This article summarizes recent experimental and numerical research by the authors on hydrodynamic and morphodynamic processes in curved river reaches, which are an example of a river configuration where three-dimensional flow processes prevail. The hydrodynamic processes include secondary flow (defined as the flow component perpendicular to the channel axis), flow separation from boundaries, shear layers and turbulence. These processes occur in natural rivers and channels and play a prominent role in, for example bends, confluences and bifurcations. These hydrodynamic processes enhance mixing and transport, but they also enhance the energy losses and thereby reduce the conveyance capacity. They have an important influence on sediment entrainment and transport and lead to the formation of zones of deposition and scour, which may affect navigability or endanger structures like bridge piers, abutments and riverbanks. They also enhance heterogeneity in substrate, flow and morphology that may enrich habitat. On geological timescales, they affect the planform evolution of the river and the development of the floodplain stratigraphy. The main objectives of the present paper are to highlight some recent findings 

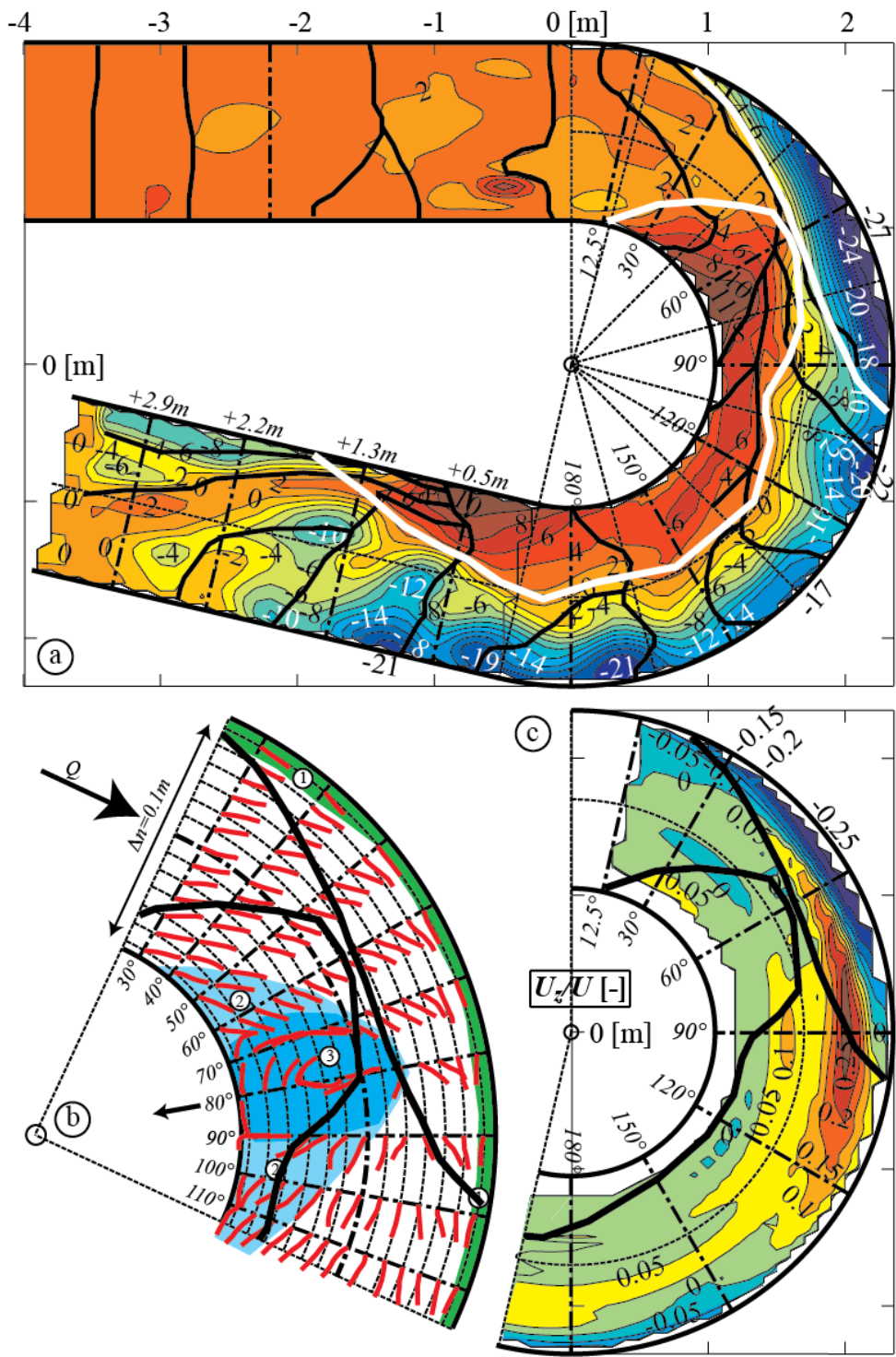

Fig. 1. Mobile bed experiments in a curved laboratory flume. (a) Bed level with an interval of $0.02 \mathrm{~m}$. The black lines indicate the position of dunes. The white lines delineate the point bar and pool. (b) Visualization of the flow at the water surface: (1) outer-bank cell of secondary flow; (2) zone of flow separation; (3) zone of flow recirculation. (c) Depth-averaged vertical velocity normalized with the flume-averaged velocity. Figure modified from Blanckaert (2010.)

and to identify some directions for future research. We refer to the references given throughout this paper for a detailed overview of the current knowledge on the investigated hydrodynamic and morphodynamic processes and their implications.

\section{Laboratory experiments}

Laboratory experiments are being performed since 1998 at Ecole Polytechnique Fédérale de Lausanne (EPFL, Switzerland) in the flume shown in Fig. 1, which was designed to be representative of sharply curved natural open-channel bends.
This flume has a width of $1.3 \mathrm{~m}$ and vertical banks. It consists of a $9 \mathrm{~m}$ long straight inflow reach, a $193^{\circ}$ bend of constant centreline radius of curvature, $R=1.7 \mathrm{~m}$, and a $5 \mathrm{~m}$ long straight outflow reach. The bed is covered with quasiuniform sediment with a mean diameter of $d=0.002 \mathrm{~m}$. Blanckaert (2010) discusses the design of the flume and its representativeness for natural open-channel bends.

This laboratory flume provides a setting with controlled flow and boundary conditions defined with an accuracy exceeding that which could possibly be obtained in a field study. A systematic series of experiments has already been performed that investigates the influence of parameters, such 
as the degree of curvature defined by the ratio of flow depth $H$ to centreline radius of curvature $R$ (Blanckaert 2009), the configuration of the bathymetry (flat fixed bed vs. develop live bed; Blanckaert 2010, 2011), the roughness of the banks (Blanckaert et al., 2012), and the inclination of the banks (Blanckaert et al., 2010; Blanckaert, 2011). Experimental data from all experiments is available from the first author.

Figure 1 shows some results in a live bed experiment with constant sediment feeding at the flume inlet, which led to a typical equilibrium bathymetry that consists of a shallow point bar at the inner side and pronounced bend scour at the outer side of the bend. Blanckaert (2010) provides a detailed description of this experiment; only the main features and processes will be briefly described hereafter.

Figure $1 \mathrm{~b}$ shows that flow separates from the inner bank downstream of the bend entry and that horizontal flow recirculation occurs over the shallow point bar. The flow recirculation eddy captures fine sediments and plays an important role with respect to accretion at the inner bank. Moreover, it reduces the effective width and directs high velocity flow towards the outer bank, thus enhancing the flow attack on the outer bank. In spite of its importance, important knowledge gaps remain with respect to flow separation and flow recirculation at curved inner banks, such as the parameters of influence, the conditions of occurrence, the dependence on the geometry and roughness of the bank, and the underlying physical processes.

Figure 1c shows the depth-averaged vertical velocity, $U_{z}$, based on measurements in the twelve indicated crosssections. These velocity measurements were performed with an Acoustic Doppler Velocity Profiler (ADVP) developed at EPFL (Lemmin and Rolland 1997, Hurther and Lemmin 1998), which measures entire vertical profiles of the quasiinstantaneous velocity vector, from which the time-averaged velocity vector and the Reynolds stress tensor can be derived. Fifty vertical profiles were measured in each of the twelve cross-sections. Blanckaert and de Vriend (2004) and Blanckaert (2010) report the data processing and estimates of the uncertainty in the experimental data. The pattern of depthaveraged vertical velocities (Figure 1c) reveals that the flow cannot follow the abrupt change in direction at the bend entrance, and collides with the outer bank at an oblique angle near the cross-section at $60^{\circ}$, resulting in abrupt flow reversal and important vertical velocities that impinge on the channel bed. Such vertical velocities impinging on the bed are similar to jets impinging on the bed, and are known to contribute significantly to the formation of the maximum bed scour (Steiner et al., 1993). Vertical velocities impinging on the channel bed that cause maximum bed scour also occur, for example, near bridge piers (Graf and Istiarto 2002) or abutments (Melville, 1992). The velocities impinging on the bed are deflected inwards near the bottom, and allow sustaining a transverse bed shape that is steeper than the angle of repose of the sediment (Blanckaert, 2011).
Zeng et al. (2008) have satisfactorily predicted the flow and the macroscopic features of the bed morphology in this experiment with a 3-D RANS flow model and EngelundHansen (1967)'s sediment transport formula. Similar to most formula for sediment transport, the Engelund-Hansen formula expresses the sediment transport rate as a function of the time-averaged bed shear stress. Engelund and Hansen calibrated their formula with data from experiments in straight laboratory flumes. The maximum bend scour and the maximum transverse bed slope, however, were underestimated. This indicates that the difficulties of 3-D morphodynamic RANS based models to predict erosion and deposition processes in loose-bed channels can largely be attributed to two factors that merit further research: (i) the empiricism of the models used to predict sediment entrainment and bedload transport, which, for example, do not account for vertical velocities impinging on the bed (ii) the use of an approach that cannot accurately capture the large-scale turbulent structures and their effects on the redistribution of the flow, the boundary shear stress and the sediment entrainment and transport.

\section{Eddy-resolving numerical simulations}

In spite of the high spatial resolution of the velocity measurements, the reported experiments could not provide all relevant information on the flow: the spatial resolution in streamwise direction is relatively low, important variables such as the boundary shear stress and pressure fluctuations are not measured, and information on coherent turbulence structures is incomplete. This information can be obtained from numerical simulations, after validation of the numerical model by means of the available experimental data. The hydrodynamics in the illustrated live bed experiment have been numerically investigated by van Balen et al. (2010a) at Delft University of Technology, and by Constantinescu et al. (2011, 2013) at the University of Iowa, by means of so-called eddyresolving techniques, which directly resolve the large scales of the turbulent motion. Van Balen et al. (2010b) and Koken et al. (2014) simulated an experiment in the same laboratory flume with similar hydraulic conditions but over flat bed topography. All of these papers include extensive comparisons of experimental data and numerical simulations for the purpose of model validation.

Figure 2 illustrates some numerical results obtained by Constantinescu et al. (2011). Figure 2a shows an instantaneous pattern of the vertical vorticity at the free surface, i.e., vortices that rotate around a vertical axis. A shear layer characterized by high vorticity is clearly visible at the edge of the zone of horizontal flow recirculation over the shallow point bar (Fig. 1b). Flow animations based on the simulation results show that vortices shedding from the downstream part of this shear layer, at times, impinge on the outer bank near 


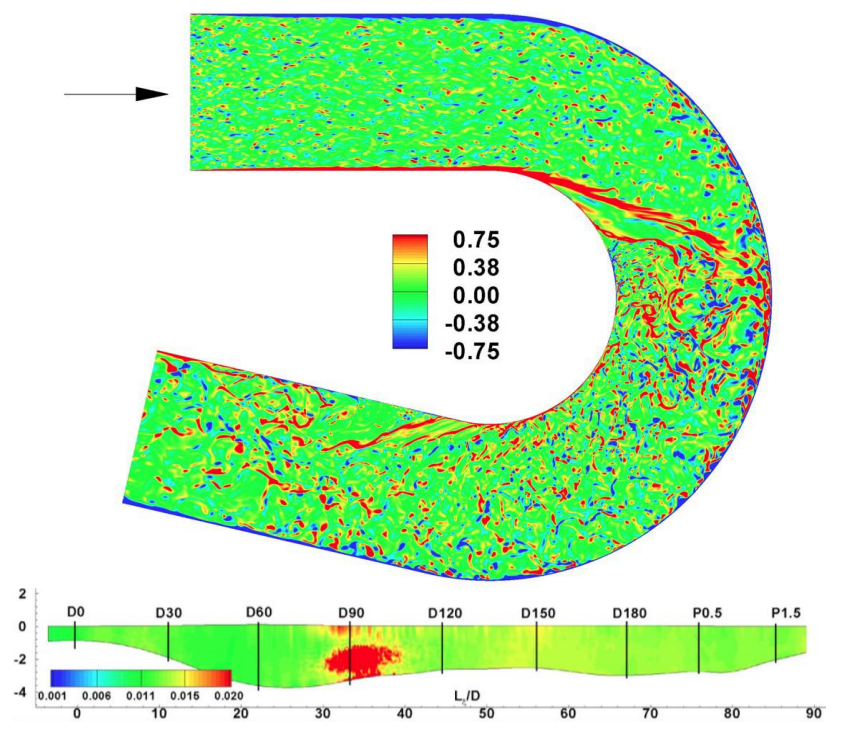

Fig. 2. Results of numerical simulations by means of Detached Eddy Simulation. (a) Instantaneous pattern of the vertical vorticity at the water surface, normalized by $U / H$ ( $U$ and $H$ are the flume-averaged velocity and flow depth, respectively). (b) Distribution of the pressure RMS fluctuations at the outer bank, normalized by $\rho^{2} U^{4}$ where $\rho$ is the water density. Modified from Constantinescu et al. (2011).

the cross-section at $90^{\circ}$ (Fig. 2a). This results in large pressure fluctuations on the outer bank (Fig. 2b).

Constantinescu et al. (2012) showed that the formation of a strong shear layer at the inner bank in which strongly coherent eddies form and are convected downstream is a general characteristic of channels containing a region where the curvature of the inner bank is high (independent of the curvature of the outer bank). They investigated by means of eddyresolving numerical simulations a confluence of two natural channels with deformed bed topography, with high innerbank curvature where one of the tributaries enters the confluence region, and low outer-bank curvature because the other tributary is aligned with the main channel. They investigated a high flow and a low flow condition. In the high flow condition, the flow in between the inner bank and the shear layer contained low velocities but no flow recirculation, i.e. no return currents in upstream direction. In the low flow condition, an elongated very shallow submerged bar formed close to the inner bank and the shear layer was located on the outer side of the submerged bar.

Koken et al. (2014) have also numerically investigated the morphological implications of highly coherent unsteady turbulent structures in the vicinity of the channel bed for the open-channel bend configuration (Fig. 1) with flat bed topography. They found that neglecting the effect of these large-scale turbulence results in a large underprediction (by about $50 \%$ ) of the mean flux of sediment entrained from the channel bed. As most 3-D simulations of open channel flow and sediment transport with movable bed are conducted with RANS codes that do not capture the unsteady dynamics of large-scale coherent turbulence structures, they also proposed a framework for accounting in an approximate way for the effect of these turbulence structures on the capacity of the flow to entrain sediment. The inclusion of the effects of coherent turbulence structures in sediment transport models would be a challenging and highly relevant research topic.

Numerical models are powerful tools for the broadening of the investigated parameter space and the generalization of the results. Changing the radius of curvature of the bend, for example, is practically not feasible in a laboratory flume, but straightforward in a numerical simulation. Ottevanger et al. (2011), for example, have performed a parameter study on the bank shear stress by means of large-eddy simulation. Results of such detailed large-eddy simulations may allow for an improved parameterization of the bank shear stress in depth-averaged or cross-sectional averaged models that are typically employed for large-scale or long-term simulations. Further numerical research with the aim of generalizing and upscaling the results of laboratory experiments and detailed numerical simulations would be highly relevant.

\section{Model for flow and morphology in open-channel bends for large-scale and long-term applications}

The computational cost of eddy-resolving flow models is still prohibitive for most practical applications. Therefore, knowledge gained from the experiments and the numerical simulations needs to be converted into practical tools for engineering. Common one-dimensional models predict the average water depth and flow velocity in each cross-section of the river. For the case of meandering rivers, one-dimensional models exist that also predict the transverse gradients of the bed profile and the velocity (Fig. 3a). A review of such models is given in Camporeale et al. (2007). Secondary flow plays an important role in the transverse redistribution of the morphology and the velocities (Fig. 3a).

Most existing models for curved open-channel flow account for the effects of the secondary flow by means of a parameterization that is based on the hypothesis of mild curvature. This parameterization prescribes the secondary flow to be proportional to the degree of curvature, quantified by means of the ratio $H / R$, whence these mild-curvature models are also called linear models. This parameterization is known to overestimate the effects of the secondary flow in moderately and strongly curved bends. Based on the enhanced insight provided by the laboratory experiments and numerical simulations, Blanckaert and de Vriend (2003, 2010) and Ottevanger et al. (2013) have developed a parameterization for the secondary flow that remains valid for moderately and strongly curved bends. Contrary to the mildcurvature models, the new parameterization accounts for the interaction between the main streamwise component of the 

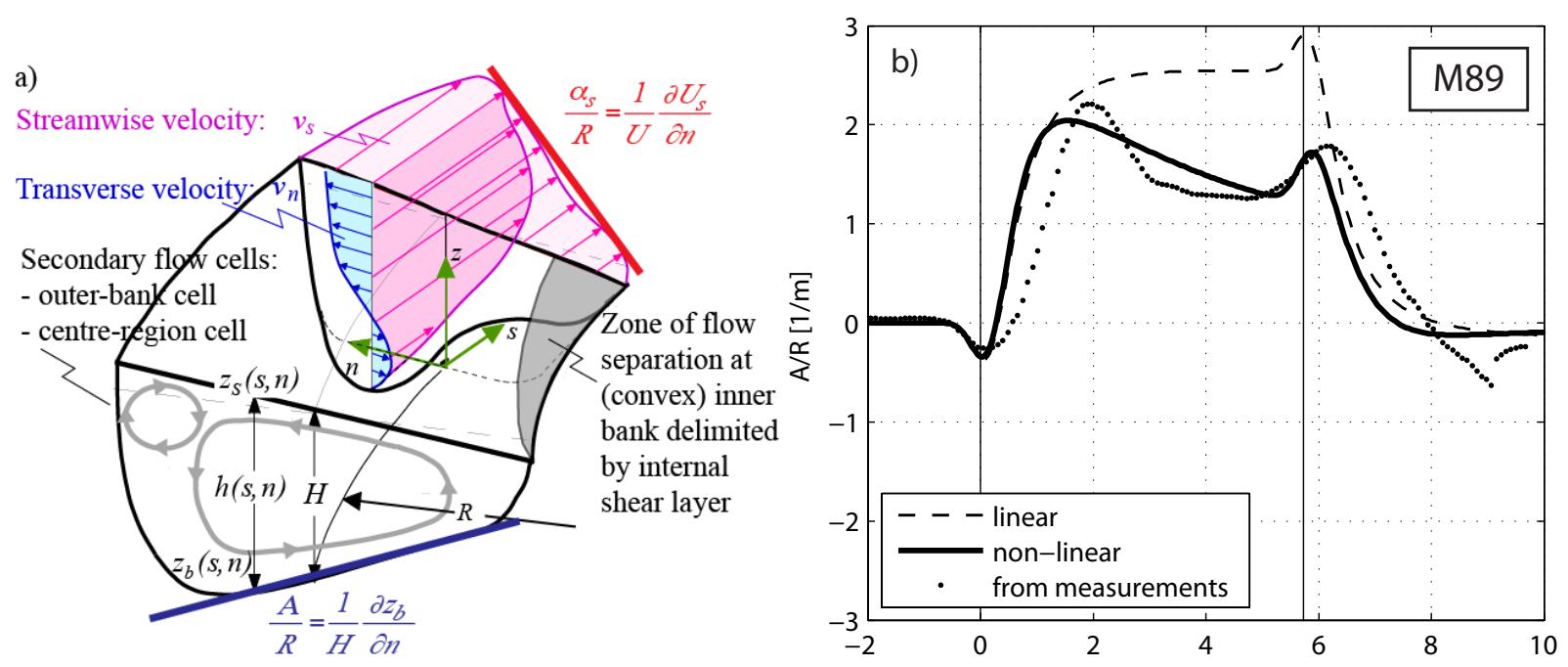

Fig. 3. (a) Conceptual representation of flow and morphology in open-channel bends. (b) Evolution around the bend of the transverse bed slope, defined as $A / R=H^{-1} \partial h / \partial n$ in the experiment shown in Fig. 1. Comparison of experimental data to simulation results with a weakcurvature model (labeled "linear") and a model without curvature restrictions (labeled "non-linear"). Modified from Ottevanger et al. (2013).

flow and the secondary flow, which causes a reduction of the magnitude of the secondary flow in moderately and strongly curved bends. The new parameterization without curvature restrictions is also called a non-linear model.

Figure $3 \mathrm{~b}$ shows the evolution of the transverse bed slope around the flume for the live bed experiment shown in Fig. 1: it compares the measured evolution to predictions by a mildcurvature linear model and the newly developed nonlinear model without curvature restrictions. The mild-curvature linear model considerably overestimate the maximum transverse bed slope in sharply curved bends, which leads to an overestimation of the maximum bend scour and the flow attack on the outer bank. The newly developed nonlinear model considerably improves the accuracy of the predictions, at only a marginal increase in computational cost.

Obviously, such a one-dimensional model can only predict the macro-scale features of the flow field and the morphology, and is intrinsically unable to resolve features on a spatial scale smaller than the channel width. Such a model is, however, a valuable practical tool. With little input information and at a low computational cost, it allows estimating the morphology and flow field. Based on the river planform, provided for example by aerial images or the design of a re-meandering scheme, it allows to identify the regions with maximum scour depth and maximum velocity that will be most vulnerable to bank erosion. The low computational cost furthermore allows large-scale and long-term simulations. When coupled to a model for bank erosion and planform evolution, the model allows investigating meander dynamics at geological timescales, including processes occurring in sharp meander bends that are close to cut-off.

An important direction for future research would be the improvement of the parameterization of the flow attack on the banks, by accounting for processes such as flow separation, pressure fluctuations, and turbulence-induced near-bank secondary flow cells (schematically shown in Fig. 3a).

\section{Modifying flow and morphology by means of bubble screens}

Curvature-induced secondary flow redistributes the flow and contributes to the development of the typical bar-pool morphology in open-channel bends. Figure 1 illustrated that vertical velocities impinging on the channel bed contribute to the development of the maximum scour. Based on the insight gained in hydrodynamic and morphodynamic processes by means of the laboratory experiments and numerical simulations, a technique has been developed that consists in counteracting the curvature-induced secondary flow by means of a bubble screen located near the outer bank. Air bubbles rise in the water column due to buoyance effects and counteract the vertical velocities impinging on the bed.

Figure 4 compares the flow field and the morphology in the cross-section at $180^{\circ}$ in the laboratory flume shown in Fig. 1 (Dugué et al. 2013). In the reference situation without bubble screen, a curvature-induced secondary flow cell occurs in the deepest part of the cross-section. Maximum scour depth is found where the vertical velocities associated with this secondary flow impinge on the bed. In the presence of a bubble screen, the rising air bubbles entrain fluid, and cause a secondary flow cell with a sense of rotation opposite to the curvature-induced secondary flow. This bubble-induced secondary flow redistributes the flow and shifts the core of highest velocities away from the outer bank. The maximum scour, core of vertical velocities impinging on the bed, and core of maximum streamwise velocities are all found near 


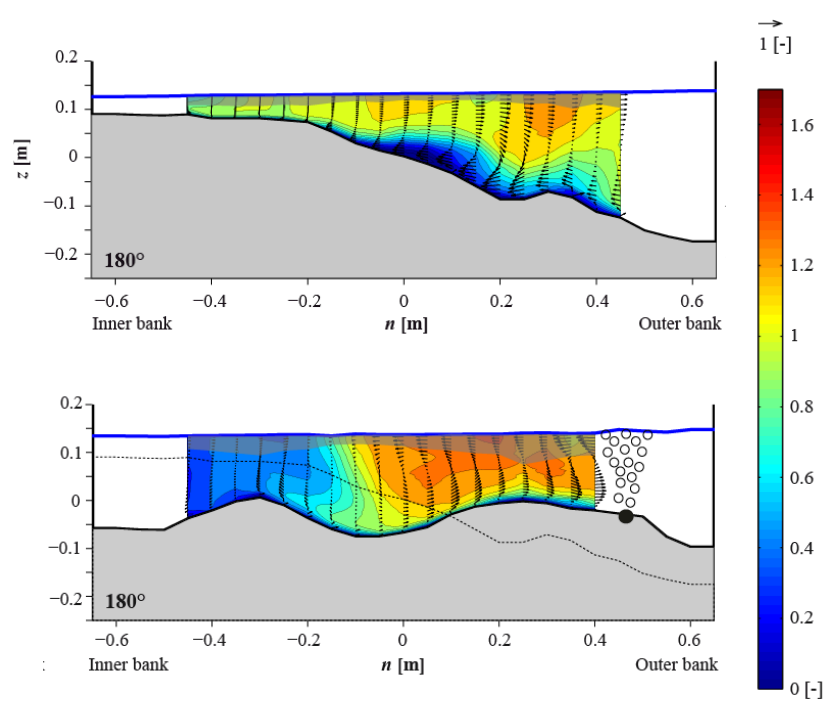

Fig. 4. Cross-section at $180^{\circ}$ in the bend shown in Fig. 1. Bed morphology, streamwise velocity normalized by the cross-sectional averaged velocity (color contours and colorbar) and vector pattern of the secondary flow normalized by the cross-sectional averaged velocity (velocity scale indicated above the colorbar). (a) Reference experiment without bubble-screen. (b) Experiment with bubble screen. Modified from Dugué et al. (2013).

the junction of the curvature-induced and the bubble-screen induced secondary flow cells. Morphological gradients are considerably reduced, as illustrated by the reduced scour near the outer bank and the reduced deposition near the inner bank.

This laboratory experiment demonstrates the capability of the bubble-screen technique to modify the flow field and the morphology. Dugué (2013) has developed a methodology to estimate the air flux required as a function of geometric and hydraulic characteristics in bends of natural rivers. The potential use of the technique is not limited to open-channel bends, but to configurations where local scour occurs due to vertical velocities impinging on the bed, such as bridge piers, abutments or obstacles in the flow. Contrary to "hard" engineering techniques, bubble screens have the advantage of being controllable, ecological (oxygenation), reversible and non-permanent. Moreover, they have no visual impact on the landscape and do no represent a threat for ships. Further research is required to investigate scale effects, estimate the range of applicability, and develop the bubble-screen technique into a practically applicable tool.

\section{Conclusions}

Recent developments in measuring technology and numerical simulation techniques have allowed gaining insight in hydrodynamic and morphodynamic processes occurring in curved open-channels, to translate the new insight into tools for river engineering and management and to develop a new technique for river engineering. The paper has illustrated some examples of recent progress related to secondary flow, flow separation and recirculation, coherent turbulence structures, and their effect on sediment entrainment and transport. Moreover, directions for future research have been identified.

Acknowledgements. The reported experimental research was funded by the Swiss National Science Foundation under grants SNF 20020-103932 and SNF 200020-119835/1. The reported numerical research by van Balen and Ottevanger was funded by Dutch Technology Foundation STW, applied science division of NWO, and the Technology Programme of the Ministry of Economic Affairs under grants DCB-6787 and DCB-7780. The research on bubble screens was funded by the Swiss National Foundation under grant 200021-125095. The first author was partially supported by the Chinese Academy of Sciences Visiting Professorship for Senior International Scientists, grant number 2011T2Z24, by the SinoSwiss Science and Technology Cooperation for the Institutional Partnership Project, grant number IP13_092911, and the Chinese National Basic Research Program 973 (2010CB429004).

Edited by: F. Métivier and Z. Dong

Reviewed by: two anonymous referees

\section{References}

Blanckaert, K.: Saturation of curvature-induced secondary flow, energy losses, and turbulence in sharp open-channel bends: Laboratory experiments, analysis, and modelling, J. Geophys. Res. Earth Surf., 114, F03015, doi:10.1029/2008JF001137, 2009.

Blanckaert, K.: Topographic steering, flow recirculation, velocity redistribution and bed topography in sharp meander bends, Water Resour. Res., 46, W09506, doi:10.1029/2009WR008303, 2010.

Blanckaert, K.: Hydrodynamic processes in sharply-curved river bends and their morphological implications, J. Geophys. Res. Earth Surf., 116, F01003, doi:10.1029/2010JF001806, 2011.

Blanckaert, K. and de Vriend, H. J.: Nonlinear modeling of mean flow redistribution in curved open channels, Water Resour. Res., 39, 1375, doi:10.1029/2003WR002068, 2003.

Blanckaert, K. and de Vriend, H. J.: Meander dynamics: A nonlinear model without curvature restrictions for flow in openchannel bends, J. Geophys. Res. Earth Surf., 115, F04011, doi:10.1029/2009JF001301, 2010.

Blanckaert, K., Duarte, A., Chen, Q., and Schleiss, A. J.: Flow processes near smooth and rough (concave) outer banks in curved open channels, J. Geophys. Res. Earth Surf., 117, F04020, doi:10.1029/2012JF002414, 2012.

Blanckaert, K., Duarte, A., and Schleiss, A. J.: Influence of shallowness, bank inclination and bank roughness on the variability of flow patterns and boundary shear stress due to secondary currents in straight open channels, Adv. Water Resour., 33, 10621074, doi:10.1016/j.advwatres.2010.06.012, 2010.

Camporeale, C., Perona, P., Porporato, A., and Ridolfi, L.: Hierarchy of models for meandering rivers and related morphodynamic processes, Reviews of Geophysics, 45, RG1001, doi:10.1029/2005RG000185, 2007. 
Constantinescu, G., Kashyap, S., Tokyay, T., Rennie, C. D., and Townsend, R. D.: Hydrodynamics processes and sediment erosion mechanisms in an open channel bend of strong curvature with deformed bathymetry, J. Geophys. Res. Earth Surf., 118, doi:10.1002/jgrf.20042, 2013.

Constantinescu, G., Koken, M., and Zeng, J.: The structure of turbulent flow in an open channel bend of strong curvature with deformed bed: insight provided by detached eddy simulation, Water Resour. Res., 47, W05515, doi:10.1029/2010WR010114, 2011.

Constantinescu, G., Miyawaki, S., Rhoads, B., and Sukhodolov, A.: Numerical analysis of the effect of momentum ratio on the dynamics and sediment-entrainment capacity of coherent flow structures at a stream confluence, J. Geophys. Res. Earth Surf., 117, F04028, doi:10.1029/2012JF002452, 2012.

Dugué, V.: Influencing River Morphodynamics by Means of a Bubble Screen: Application to Open-Channel Bends, Thèse no 5676, Ecole Polytechnique Fédérale Lausanne, Lausanne, Swizterland , 2013.

Dugué, V., Blanckaert, K., Chen, Q., and Schleiss, A.J.: Reduction of bend scour with an air-bubble screen - morphology and flow patterns. International Journal of Sediment Research, 28(1), 1523, 2013.

Engelund, F. and Hansen, E.: A monograph on sediment transport in alluvial streams, Danish Technical Press, 1967.

Graf, W. H. and Istiarto, I.: Flow pattern in the scour hole around a cylinder, J. Hydr. Res., 40, 13-20, 2002.

Hurther, D. and Lemmin, U.: A constant-beam-width transducer for 3D acoustic Doppler profile measurements in open-channel flows, Meas. Sci. Technol., 9, 1706-1714, doi:10.1088/09570233/9/10/010, 1998.
Koken, M., Constntinescu, G., and Blanckaert, K.: Hydrodynamic processes, sediment erosion mechanisms and Reynolds number induced scale effects in an open channel bend of strong curvature with flat bathymetry, J. Geophys. Res.-Earth, doi:10.1002/2013JF002760, 2014.

Lemmin, U. and Rolland, T.: Acoustic velocity profiler for laboratory and field studies, J. Hydraul. Eng., 123, 1089-1098, doi:10.1061/(ASCE)0733-9429(1997)123:12(1089), 1997.

Melville, B. W.: Local Scour at Bridge Abutments, J. Hydraul. Eng., 118, 615-631, 1992.

Ottevanger, W., Blanckaert, K., and Uijttewaal, W. S. J.: A parameter study on bank shear stresses in curved open channel flow by means of large-eddy simulation, River, Coastal and Estuarine Morphodynamics: RCEM 2011, 1917-1927, Tsinghua University Press, Beijing, China, 2011.

Ottevanger, W., Blanckaert, K., Uijttewaal, W. S. J., and de Vriend, H. J.: Meander dynamics: a reduced order nonlinear model without curvature restrictions for flow and bed morphology, J. Geophys. Res. Earth Surf., 118, F20080, doi:10.1002/jgrf.20080, 2013.

Steiner, O. R., Alonso, C. V., and Julien P. Y.: Mechanics of jet scour downstream of a headcut, J. Hydr. Res., 31, 723-738, 1993.

Van Balen, W., Uijttewaal, W. S. J., and Blanckaert, K.: Largeeddy simulation of a curved open-channel flow over topography, Physics of Fluids, 22, 075108, doi:10.1063/1.3459152, 2010a.

van Balen, W., Blanckaert, K., and Uijttewaal, W. S. J.: Analysis of the role of turbulence in curved open-channel flow at different water depths by means of experiments, LES and RANS. J. Turbul., 11, doi:10.1080/14685241003789404, 2010b.

Zeng, J., Constantinescu, G., Blanckaert, K., and Weber, L.: Flow and bathymetry in sharp open channel bends: experiments and predictions, Water Resour. Res., 44, W09401, doi:10.1029/2007WR006303, 2008. 